MATEC Web of Conferences 9, 06004 (2013)

DOI: $10.1051 /$ matecconf/20130906004

(C) Owned by the authors, published by EDP Sciences, 2013

\title{
Artificial and natural weathering of fire proofed wood cladding
}

\author{
Christophe Belloncle ${ }^{1, a}$, Mark Irle ${ }^{1}$ and Jean-Baptiste Aurel ${ }^{2, a}$ \\ 1 LUNAM Université, Ecole Supérieure du Bois, rue C. Pauc, 44306 Nantes, France \\ 2 WOODENHA, Port de Cheviré, 44000 Nantes, France
}

\section{INTRODUCTION}

Using wood in the French construction industry is not a fade but a real trend and this natural raw material is being used more frequently, especially in public or community buildings. As France has strict and demanding fire regulations, all construction materials, including wood, should comply with these rules (1). Even though wood is a very versatile and unique material, one of its weaknesses is poor fire reaction. This issue has to be solved for certain wood applications such as cladding.

Effectiveness of treatment is well documented, however little information on fire reaction behaviour in real exterior conditions compared to artificial weathering can be found in the literature. An intensive and collective work has been published (2) (3) leading to a proposal of a new weathering procedure, that requires complex, newly design equipment (4) (5). Since this equipment is not readily available, this research uses techniques designed for testing finishes (6).

The aim of this work is to investigate the applicability of these methods to basic boron and phosphorous-treated wood products and a new generation of products intended for exterior use.

\section{MATERIAL AND CONDITIONING}

\section{Wood samples and FR treatment}

Claddings made from Douglas fir were used as wood material reference. Samples were $21 \mathrm{~mm}$ thick $150 \mathrm{~mm}$ wide and $800 \mathrm{~mm}$ long. All samples were conditioned in a climatic chamber $\left(23^{\circ} \mathrm{C}\right.$ and $50 \%$ RH) before use.

All samples were pressure treated in a 50 litre laboratory pressure vessel. Vacuum was applied for $20 \mathrm{~min}$, followed by flooding and pressure treatment (9 bars for $60 \mathrm{~min})$. A final vacuum (10 min) was applied to remove excess product. Five pieces were treated at the same time and a total of 20 were used for the different experiments.

Three fire resistant formulations were tested. The first 2 are commercial products referenced as B1 and P1 each containing a mixture of boron and phosphate salts and a phosphorous based product respectively. Both products were used as indicated in their respective technical data sheets. The dry content was $25 \%$ for both and value is considered as equivalent to the active ingredient content. Retention in wood, based on active ingredient (AI), was calculated, based on weight gain of sample.

$\mathrm{B} 1$ product is designed to be used in applications where wood is protected from direct leaching with water. This normally excludes many uses like cladding. However such uses are quite common and B1

\footnotetext{
ae-mail: christophe.belloncle@ecoledubois.fr

be-mail: jb.aurel@woodenha.com
}

This is an Open Access article distributed under the terms of the Creative Commons Attribution License 2.0, which permits unrestricted use, distribution, and reproduction in any medium, provided the original work is properly cited. 


\section{MATEC Web of Conferences}

Table 1. Samples references and treatement products.

\begin{tabular}{|l|l|l|l|}
\hline Reference & FR chemicals & Active Ingredient (AI) & \\
\hline B1 & $\begin{array}{l}\text { Boron salts } \\
\text { Phosphorous salts }\end{array}$ & $25 \%$ & \\
\hline P1 & Phosphorous based product & $25 \%$ & $\begin{array}{l}\text { Phosphorous based product } \\
\text { Reactive chemical }\end{array}$ \\
\hline P2 & $27.5 \%$ & \\
\hline
\end{tabular}

is applied to many wood claddings of protected buildings. One of the solutions to enhance potential application is to finish the product with specific top coat. Because the aim of that project is to test weathering FR wood, such kind of product was brushed to the surface with an aqueous topcoat based on alkyde-urethane resin.

The commercial P1 product was modified by adding wood reactive chemicals to create a third treatment termed P2in this paper. The dry content of the formulation was $27.5 \%$. Retention in wood, based on dry content was also calculated.

Samples were all kiln dried with a temperature program up to $70^{\circ} \mathrm{C}$ to $\mathrm{EMC}$ to $13 \%$ and conditioning for 4 weeks before further testing.

Penetration of FR products into the wood has been monitor using EDX analyses. Qualitative measurement on a $2.2 \mathrm{~mm}^{2}$ transversal wood cut surface using mapping tool shows the phosphorous response throughout the wood cell cut. P1 and P2 were monitored the same way and no significant differences were noted.

Samples were weathered according to EN 927 (-3 and -6) before being fire tested, leading to 3 sets of results: not weathered, naturally weathered and artificially weathered. EN84 was used as screening test for uncoated wood samples.

\section{Fire reaction tests}

Samples were fire tested according to NF P 92-501 (7) (Radiant panel). Some were tested according to EN 13823 (8) (Single Burning Item, SBI).

SBI uses a large surface of wood and is claimed to be closer to a real fire situation. SBI is only used as initial test to determine the class of the product using European standard. In this paper, SBI has only been used for one product, B1, as a reference.

NF P92-501 is used in this work as a routine test to check changes of fire resistance after ageing. It is dedicated to materials with a minimum thickness of $5 \mathrm{~mm}$ and uses a $0.12 \mathrm{~m}^{2}$ surface. The wood sample is not directly exposed to the flame.

Samples are submitted to radiant heat to induce inflammation of VOC. Propagation of the combustion is measured as well as heat from material combustion. The sample is orientated $\left(45^{\circ}\right)$ and located at $30 \mathrm{~mm}$ from heat radiant device. Inflammation devices are located from each side of the sample to ignite pyrolysis gaz.

Tests last $20 \mathrm{~min}$. Ignition delay $(\mathbf{T i})$, combustion time $(\Delta \mathbf{t})$ as well as flame heights $(\mathbf{h})$, are recorded to define the indicator $\mathbf{q}$ that is define as:

$$
q=\frac{100 \cdot \sum h}{T_{i} * \sqrt{\Delta t}} .
$$

The $\mathrm{q}$ indicator gives $\mathrm{M}$ classification according to the standard. $\mathbf{q}=2.5$ and $\mathbf{q}=15$ are respectively used as the limits between M1 and M2 class and M2 and M3 class. Only three replicates are needed to validate the M class. 
Table 2. Relation between Euroclass and the French M class (adapted from French Government "arrêté du 21 nov. 2002").

\begin{tabular}{|c|c|c|c|}
\hline \multicolumn{3}{|c|}{ Class according NF EN 13501-1 } & Class according NF P92 \\
\hline A1 & - & - & not combustible \\
\hline $\mathrm{A} 2$ & s1 & $\mathrm{d} 0$ & M0 \\
\hline A2 & s1 & d1 & \multirow{6}{*}{ M1 } \\
\hline A2 2 & s2 & d0 & \\
\hline A2 & s3 & $\mathrm{d} 1$ & \\
\hline \multirow{3}{*}{$\mathrm{B}$} & s1 & & \\
\hline & s2 & $\mathrm{d} 0$ & \\
\hline & s3 & $\mathrm{d} 1$ & \\
\hline \multirow{3}{*}{$\mathrm{C}$} & s1 & & \multirow[b]{3}{*}{ M2 } \\
\hline & s2 & $\mathrm{d} 0$ & \\
\hline & s3 & $\mathrm{d} 1$ & \\
\hline \multirow{3}{*}{$\mathrm{D}$} & s1 & & \multirow[b]{3}{*}{ M4 (no drop) } \\
\hline & s2 & d0 & \\
\hline & s3 & $\mathrm{d} 1$ & \\
\hline $\mathrm{E}$ & \multicolumn{2}{|c|}{ all except E-d2 and F } & M4 \\
\hline
\end{tabular}

A relation between Euroclass and $\mathrm{M}$ classification is given in Table 2 as described by French regulations. The official correspondence is one way: Euroclass to $\mathrm{M}$, but it can be reckoning that a proper behaviour to $\mathrm{M}$ testing would give decent result to SBI.

\section{RESULTS AND DISCUSSION}

Samples treatments with the three formulations were done according to the same protocol, usually used for B1 treatment. No differences were noted during the pressure/vacuum cycle. Solutions were stable and the same batch was used for all the 20 samples.

All retentions that have been calculated as described previously are of the same order of magnitude. However when $\mathrm{P} 1$ and $\mathrm{P} 2$ results indicate $45 \mathrm{~kg} / \mathrm{m}^{3}, \mathrm{~B} 1$ is observed to be 30 to $35 \mathrm{~kg} / \mathrm{m}^{3}$ (Table 3 ). That difference, even low, indicates a 50\% increase for P1 and P2. Obviously, this is not linked to the dry content of each formulation (both B1 and P1 have the same dry matter content), but may be linked to some additives (surfactants for example) or by-products even in low concentration that induce a better penetration.

As a matter of fact B1 has been studied and is used for a very long time leading to well defined treatment protocol. On the contrary P1 and P2 need to be further studied to set up a correct pressure cycle. Because FR treatments are usually set in the range 30 to $50 \mathrm{~kg} / \mathrm{m}^{3}$, it was decided that results obtained were good enough to be representative of an industrial production.

Since B1 is not design for outdoor application a full system was studied as a reference: a top coat was applied to the samples to prevent leaching or strong weathering of the product. Because P2 is specially design to be used outdoor and P1 is a control product for P1, no finishing were applied.

P1 formulation is derived from other material application and is not thoroughly used in wood industry. It is mainly an indoor product, but one of its advantages is to avoid the use of boron products. Boron salts are subject to cautious and substitution will be probably compulsory in the future. It is proven that $\mathrm{P} 1$ formulation fulfils the M 2 criteria after treatment to c.a. $45 \mathrm{~kg} / \mathrm{m} 3$.

The change of the formulation of P1 is driven by a possible use in outdoor situation. Chemically reactive products known to react with wood and various functional chemicals at moderate temperature 
MATEC Web of Conferences

Table 3. Wood treatment and M class according to EN and NF P 92-501.

\begin{tabular}{|l|l|l|l|l|}
\hline Reference & untreated Douglas Fir & B1 + topcoat & P1 & P2 \\
\hline FR retention $(\mathrm{kg} / \mathrm{m} 3)$ & - & $30-35$ & $46+/-10$ & $45+/-10$ \\
\hline Classe according to NFP92501 & M3 & M2 & M2 & M2 \\
\hline$Q$ & $45.0 \pm 15.6$ & $2.9 \pm 2.0$ & $6.5 \pm 4.0$ & $3.2 \pm 2.3$ \\
\hline number of replicates & 2 & 4 & 4 & 6 \\
\hline Class according to SBI & $\mathrm{D}(9)$ & & - & - \\
\hline
\end{tabular}

Table 4. Results of NFP for each replicate P2.

\begin{tabular}{|l|l|l|l|l|}
\hline & Retention $(\mathrm{kg} / \mathrm{m} 3)$ & Density $(\mathrm{kg} / \mathrm{m} 3)$ & Q & M Class \\
\hline Replicate 1 & 53.61 & ND & 1.49 & M1 \\
\hline Replicate 2 & 50.78 & 548 & 6.73 & M2 \\
\hline Replicate 3 & 49.98 & 518 & 5.68 & M2 \\
\hline Replicate 4 & 44.7 & 554 & 2.75 & M2 \\
\hline Replicate 5 & 39.33 & 477 & 1.45 & M1 \\
\hline Replicate 6 & 31.39 & 519 & 1.38 & M1 \\
\hline
\end{tabular}

were added to the formulation taking care of the stability of the solution. The aim was to trap active FR compound inside wood, making chemical bridges between wood and wood, wood and AI, AI and AI. After the treatment, kiln drying, up to $70^{\circ} \mathrm{C}$, was done following classical profile for softwood.

Initial fire tests were then performed according to NFP92-501 on the three treated wood and an untreated one. Table 3 shows both qualitative and quantitative results. All products are active regarding to untreated wood which is classified as expected as M3.

M2 class was obtained for all treated wood regardless the treatment but some differences in q value should be highlighted. Close to the M1 limit value for the B1 and P2 treated samples a large deviation is observed. 6 replicates from P2 were tested and half of them gave a good M1 result as shown in Table 4

All samples were done on the same wood lot, using the same preservative batch. The density measurement as well as FR content do not show significant trend.

Because P1 product does not behave that way, (all samples being far from the q limit of 2.5 used to distinguish between M1 and M2), added chemicals are supposed to act partially as FR retardant.

Up to date no information about that large variation is arising from our work, but more replicates will be done to evaluate the variability of the treatment due to wood itself.

\section{Leaching test according to EN84 standard}

EN84 is a very severe test that lasts only 4 weeks including a drying process of 2 . It makes a good routine control of the effectiveness of an AI added to a porous compound.

Preservative treatment effectiveness is controlled after such kind of test. During 14 days, wood is damped into distilled water that is changed every day except Saturday and Sunday. To avoid possible cross contamination, only one reference is allowed per leaching tank. The volume ratio wood/water is kept constant during test and in accordance with standard.

As presented in Tabel 5, the decrease is around 3 in q value from both formulations leading to a value for $\mathrm{P} 2$ that is close to the value obtained for the P1 initial test. The M class is less discriminant and both products are labelled as M2 products.

The added chemical to P1 is claimed to block the FR product into the wood. Retention loss values are calculated from weight measurement before and after leaching with respect to the conditioning time. Values are varying a lot (up to 50\% difference between replicates!). However P1 and P2 behave 
Table 5. Results of leaching test EN84 on $\mathrm{P}$ and $\mathrm{P} 2$ treated wood.

\begin{tabular}{|l|l|l|l|l|}
\hline Reference & \multicolumn{2}{l|}{ P1 } & P2 \\
\hline Ageing & none & EN84 & none & EN84 \\
\hline Class according to NF92 & M2 & M2 & M2 & M2 \\
\hline Q & 6.5 & 9.0 & 3.25 & 6.69 \\
\hline Variation of Q & & 2,47 & & 3.44 \\
\hline Treatment loss (range)* & & $20-70 \%$ & & $9-15 \%$ \\
\hline Number of replicates & 4 & 3 & 6 & 3 \\
\hline
\end{tabular}

* Based on mass variation and calculated on retention value.

Table 6. Results from weathering test of B1 and P2 treated wood.

\begin{tabular}{|l||l|l|l|l|l|l|l|}
\hline Reference & wood & B1+ topcoat & B1+ topcoat & B1 + topcoat & P2 & P2 & P2 \\
\hline Weathering & none & none & EN 927-6 & EN 927-3 & none & EN 927-6 & EN 927-3 \\
\hline M Class (NF P 92-501) & M3 & M2 & M2 & M2 & M2 & M2 & M2 \\
\hline $\mathrm{q}$ & 45 & 3.9 & 10.5 & 8.4 & 3.2 & 11.1 & \\
\hline$\Delta \mathrm{q}$ & & - & 6.7 & & - & 7.9 & \\
\hline Number of replicates & 2 & 4 & 4 & 4 & 4 & 4 & 4 \\
\hline
\end{tabular}

differently: $\max 15 \%$ for P2 and no less than $20 \%$ for P1. Combined to the q value, new formulation could be a good solution for outdoor applications.

As a matter of fact, one replicate from P2 is remaining class M1 with a q value as low as 0.3. Added to the fact that initial results are also at the edge for the class M1, the product is believe to be at the edge of the M1/M2 limit.

\section{Weathering according to EN 927-3 and EN 927-6}

Because P2 was seen to keep a good activity, exposure to artificial and natural weathering was performed on B1 and P2, according EN927-3 and -6 standards. Artificial exposure mainly consists of short cycles ( 3 hours) of UV light exposure $(2.5 \mathrm{hr})$ and pulverisation exposure $(0.5 \mathrm{hr})$ during 12 weeks. Each week a one day condensation cycle is added. Natural exposure $\left(45^{\circ}\right)$ of one year was done for B1 and is currently on going for P2.

Results are shown in Table 6. Artificial weathering of B1 shows that it remains in the M2 class. The difference between the $q$ values before and after weathering is less than 7 (6.7) indicating a good resistance to leaching but moreover to surface degradation. Visual inspection of the surface does show a significant change in roughness as well as in colour. The coating seems to have protected the product very well even though no measurements of colour or gloss resistance have been done.

Natural weathering follows the same trend with a $\Delta \mathrm{q}$ of only 4.5. Previous study (10) has shown that artificial weathering compared to natural was a function of the coating resin. An average of 2 years is generally taken for comparison purpose. Exposure tests are continuing.

Results for P2 are a little bit less positive with a $\Delta \mathrm{q}$ of 7.9. However these samples were coating free. Roughness of the surface is definitely increasing having an effect on the ignition delay and the combustion time. Colour of the samples turned to a homogeneous grey has expected. Unfortunately natural exposure has not reached its first year. Visual inspection after 10 months shows a better aspect in term of roughness. Good results are expected beginning of October 2013. Also comparative results are expected beginning of November 2013 with initial SBI and EN-927-3. 


\section{MATEC Web of Conferences}

\section{CONCLUSION}

PrEN 15912 (5) is probably the next standard to validate the long term reaction to fire property of wood product. In the meanwhile, EN 927-6 was used as an artificial test to evaluate that property. Because that test is 12 weeks long, EN84 was applied as a screening test to a new formulation. The new boron free formulation has demonstrated good resistance to leaching as well as ability to fire reaction properties. However, natural exposure has to be completed to insure definitive validation.

\section{References}

[1] Anonymous, Cabinet CASSO \& Cie., Sécurité contre l'incenie dans les ERP. Techniques de l'Ingénieur. 2008, C3280v2.

[2] Östman B, Voss A, Hughes A, Hovde P J, Grexa O, Durability of fire retardant treated wood products at humid and exterior conditions - Review of literature. Fire and Materials. 2001, Vol. 25, 3, pp. 95-104.

[3] Hakkarainen, Tuula, InnoFire Wood, State-of-the-art. 2005.

[4] NTBuild495, Building materials and components in the vertical position: Exposure to accelerated climatic strains.

[5] 175, CEN/TC, Pr NF EN 15912. 2009.

[6] EN927, Peintures et vernis - Produits de peinture et systèmes de peinture pour bois en extérieur. 2012.

[7] NFP92-501, Safety against fire - Building materials - Reaction to fire tests Radiation test used for rigid materials, or for materials on rigid substrates (flooring and finishes) of all thicknesses, and for flexible materials thicker that $5 \mathrm{~mm} .1995$.

[8] NFEN13823, Reaction to fire tests for building products - Building products excluding floorings exposed to the thermal attack by a single burning item. 2013.

[9] GAILLARD, Jean-Marie, Amélioration de la performance en réaction au feu des bardages bois. FCBA Info. 2012.

[10] Laurence Podgorski, Martin Arnold, Guido Hora, Artificial weathering test for wood coatings. Coatings world. 2003, p. 39. 